\title{
Erectile Dysfunction and Correlates Among Diabetic Men at Dessie Referral Hospital: North Central Ethiopia, 2020
}

This article was published in the following Dove Press journal: Diabetes, Metabolic Syndrome and Obesity: Targets and Therapy

\author{
Shiferaw Abeway (D) \\ Kefyalew Dagne ${ }^{2,3}$ \\ Tazeb Zegeye ${ }^{4}$ \\ 'School of Nursing and Midwifery, \\ Department of Pediatric and Child Health \\ Nursing, College of Medicine and Health \\ Sciences, Wollo University, Dessie, \\ Ethiopia; ${ }^{2}$ Department of Psychiatry, \\ College of Health Sciences and Medicine, \\ Debre Berhan University, Debre Berhan, \\ Ethiopia; ${ }^{3}$ Department of Psychiatry, \\ School of Medicine, College of Health \\ Sciences, Addis Ababa University, Addis \\ Ababa, Ethiopia; ${ }^{4}$ School of Medicine, \\ College of Medicine and Health Science, \\ Wollo University, Dessie, Ethiopia
}

Background: Erectile dysfunction is currently one of the most common sexual dysfunctions worldwide affecting the quality of life of men of all ages, but it is usually underestimated because it is not a life threatening condition.

Purpose: This study aims to determine the prevalence of erectile dysfunction and the possible correlates among diabetic men in Dessie Referral Hospital, North Central Ethiopia.

Methods: An institution-based cross-sectional study was conducted among diabetic men aged greater than 18 years, at Dessie Referral Hospital. Systematic random sampling technique was used to select study participants. A pre-tested and structured questionnaire was used to collect the data. Data were entered in Epi Info version 7 and analyzed using SPSS version 21. Logistic regression was applied to identify association between explanatory variables and the outcome variable. An adjusted odds ratio with $95 \%$ confidence interval and p-value less than 0.05 was computed to determine the level of significance.

Results: Overall, the prevalence of erectile dysfunction (ED) in this study was $58.5 \%$ at 95\% CI (0.548-0.622), and specifically $10.5 \%, 40.9 \%, 6.8 \%$ respondents had mild, moderate and severe erectile dysfunction, respectively. Age, duration of diabetes diagnosis, types of medication, types of complication and body mass index were significant unadjusted factors associated with erectile dysfunction, but following adjustment only age [AOR $=5.5(95 \% \mathrm{CI}$ 2.06-14.744), duration of diabetes $[\mathrm{AOR}=20,(95 \%$ CI 5.663-75.0096) and types of medication $[\mathrm{AOR}=2.106(95 \% \mathrm{CI} 1.112-3.988)$ have independently statistically significant association with erectile dysfunction.

Conclusion: This study showed that ED is high. Age, duration of diabetes mellitus and type of medication are independently associated with erectile dysfunction. Health policymakers need to consider including the training of health personnel to consider the relevant risk factors during the physical, social and psychological assessment of patients, and clinicians should pay attention to the sexual history of their client.

Keywords: diabetes, erectile dysfunction, Dessie

\section{Introduction}

Reproduction is a biological process by which new individuals are produced, and sexual reproduction requires sexual interaction by two specialized organisms. For practicing sexual intercourse effective hydraulic action of the penis is very important. However, erection of the penis can be affected by various endogenous and exogenous factors. ${ }^{1}$
Correspondence: Shiferaw Abeway School of Nursing and Midwifery, Department of Pediatric and Child Health Nursing, College of Medicine and Health Sciences, Wollo University, Dessie, Ethiopia Tel +251931614769

Email shifeby@gmail.com
Diabetes, Metabolic Syndrome and Obesity: Targets and Therapy 2020:1 3 420I-4208 
Erectile dysfunction (ED) is known to be one of the pressing problems faced by people with diabetes. A study result shows that $75 \%$ of men who live with diabetes are exposed to erectile dysfunction in their earlier ages as compared to non-diabetic men. Even if the risk of erectile dysfunction increases with age for all men, it appears to be higher among diabetic men. ${ }^{2}$

Researches confirmed that higher rates of ED are related with different types of chronic illnesses such as diabetes mellitus (DM), cardiovascular disease and depression, where DM appears to be a major determinant. ${ }^{3,4}$

In the United States, the Massachusetts Male Aging Study had shown that the risk of ED is increased by age, lower education, diabetes, heart disease, and hypertension.

Erectile dysfunction is a common complication of diabetes. It is estimated that over $75 \%$ of diabetic men will be affected at some time in their lives with a consistent or recurrent inability to achieve and maintain an erection adequate for sexual performance, typically at an earlier age than non-diabetic men. ${ }^{2}$ While the incidence of ED increases proportionately with age in the general population, the gradient is particularly steep in diabetic men as they appear to have more severe dysfunction. ${ }^{2}$ In the United States alone, over $53 \%$ of diabetic men are affected with ED. ${ }^{5}$ Research suggests that there is a significant relationship between ED and DM in men and the estimated prevalence of ED in diabetic men has been reported to range from 20 to $71 \%{ }^{6,7}$ Oyelade et al, reported that men with DM were more than twice as likely to have ED compared to men without diabetes. ${ }^{8}$

ED can occur early in the course of the disease and it can occasionally be the presenting symptom. ${ }^{9}$ Some documented reports give the main risk factors of ED in people with diabetes as neuropathy, vascular insufficiency, poor glycemic control, hypertension, low testosterone levels, and lifestyle factors such as smoking, alcohol and inactivity. In addition the prevalence of ED greatly increases with age. $^{10,11}$

A wide range of prevalence rates of ED among diabetic men has been reported in various studies. These studies $^{8,11,12}$ suggest that its prevalence in men with diabetes ranges from $35-90 \%$ versus $26 \%$ in the general population. West and East Africa have demonstrated that the prevalence of ED in men with DM is high. ${ }^{8,12}$

ED is classified into organic and psychogenic subtypes, of which the organic subdivision is often caused by a variety of factors including DM, hypertension, cardiovascular diseases, traumatic/post-surgical, hormone- induced, drug-induced and hyperlipidemia. Psychogenic includes depression, relationship problems, and performance anxiety. This is somewhat less frequent, in the order of about $10 \%$ of cases. ${ }^{1}$

The prevalence of DM in Africa continues to rise, thus imposing an extra burden on Africa's healthcare systems. Mortality and morbidity in patients with DM are often the result of both micro- and macro-vascular complications. One common and yet underestimated complication of DM is ED. ${ }^{13}$ The pathophysiology of ED in DM is related to multiple mechanisms, including endothelial dysfunction, the accumulation of advanced glycation end products, oxidative stress, and autonomic neuropathy. For instance, diabetes may affect the cavernous nerve terminals and endothelial cells, resulting in a deficiency in neurotransmitters. ${ }^{14}$

Hypertension and erectile dysfunction are closely intertwined diseases, which have endothelial dysfunction as a common base. During hypertension and/or erectile dysfunction, disturbance of endothelium-derived factors can lead to an increase in vascular smooth muscle (VSM) contraction. Hypertension can lead to erectile dysfunction as a consequence of high blood pressure (BP) or due to antihypertensive treatment. However, growing evidence suggests erectile dysfunction is an early sign for hypertension. Also, some phosphodiesterase-5 inhibitors used to treat erectile dysfunction can improve BP, but the link between these conditions has not been totally understood. ${ }^{15}$

Since chronic medical illnesses are becoming increasingly prevalent in our setting, a clinic based study of magnitude ED among men who have demonstrated a health-seeking behavior was not studied in Ethiopia. Therefore the result of this study should give insight for researchers, policy makers, health planers, and responsible bodies.

\section{Study Area and Period}

The study was conducted in Dessie town which is found in North Wollo Zone, Amhara regional state, north east central Ethiopia. Dessie town is $401 \mathrm{~km}$ from Addis Ababa, a capital city of Ethiopia Dessie Town has 151,154 population sizes off which 78,242 are females and 72,932 are males. Dessie Referral Hospital has more than 10 wards and more than 20 clinical services giving services for more than eight million people. Dessie Tertiary Hospital has 610 health care workers and 220 supporting workers. The study was conducted from March to June, 2020. 


\section{Inclusion and Exclusion Criteria Inclusion Criteria}

- All diabetic men clients attending the diabetic clinic.

- Patients who were eligible for participation included men with type 1 and type 2 diabetes receiving pharmacological treatment for the disease.

\section{Exclusion Criteria}

- Mentally ill individuals with DM and seriously ill during data collection.

- Past lower urinary tract or urethral/penile surgery.

- History of pelvic and spine injury.

\section{Sample Size Determination and Sampling Procedure}

The sample size was determined using single population proportion formula. The proportion of ED on the previous study conducted in Central and Northwestern Zone of Tigray was $69.9 \% .^{23}$ Thus with $95 \%$ confidence level, and $10 \%$ possible nonresponse rate, making the final sample size was found to be 323 .

The study was conducted by using systematic random sampling method was employed to recruit participants.

\section{Sampling Procedure}

The study was conducted by using systematic random sampling method. On average the number of patients seen at diabetic clinic were about 28 per day, i.e. around 1848 patient within three months. Dividing the total number of patients seen within three months (1848) by the sample size (323), the interval will be five. Every fifth patient was selected and interviewed in a separate room prepared for DM patients before receiving their regular clinical services. The first patients that should be included in the sample were chosen randomly by lottery method.

\section{Data Collection Procedure}

Data was collected by face-to-face interview using a structured interviewer administered questionnaire which included the abridged five-item version of the International Index of Erectile Function (IIEF-5). The questionnaire first prepared in English and translated to Amharic, and finally back-translated to English. Three diploma-holding nurse professionals were used to collect data. Two BSC Nurses were assigned to supervise the data collection process. Both the data collectors and supervisors were given training before the actual work, about the aim of the study, procedures and collection techniques.

\section{Quality Assurance}

Pre-testing of the questionnaire was undertaken in 5\% of the sample size out of the study area in Haik Primary Hospital (30 km away from the study site) before the actual data collection and corrections on the instruments was made accordingly. The data were collected by trained data collectors. Overall activity was controlled by the principal investigator.

\section{Data Processing and Data Analysis}

The data were checked for completeness and consistency. Data cleaning was done manually by removing missing ideas and responses to questions about relevant information. Data entered into Epi Info version 7 and exported to SPSS version 21. Descriptive statistics was used for variables in the study using statistical parameters frequencies, percentage, tables and figures. Bivariate analysis was used to see the association between independent and dependent variables with statistical significance of $(p<0.2)$. Variables found to have an association with the dependent variables then entered into multivariable regressions and those variables with p-value less than or equal to 0.05 (p-value $\leq 0.05$ ) was considered statically significant. Additionally, the odds ratio calculation at $95 \%$ confidence interval used to measure strength of association.

\section{Ethical Considerations}

Ethical clearance was obtained from the institutional ethical committee of Wollo University. Formal letter of cooperation was written for Regional Health Bureau, Dessie Health Office and Dessie Referral Hospital and permission was obtained. Written informed consent was obtained from each respondent, each respondent was informed about the objective of the study that it contributed to improve sexual health. All participants provided informed consent, and this study was conducted in accordance with the Declaration of Helsinki, a a statement of ethical principles for medical research involving human subjects. Any respondent who was not willing to participate in the study has not been forced to participate.

\section{Result \\ Socio-Demographic Characteristics}

Majority of participants $(85.1 \%)$ were married. Out of the total respondents, $72.8 \%$ were Muslim religion followers. About $30.3 \%$ of participant had completed their education at college level and above. About $30.7 \%$ were government employees (Table 1). 


\section{$\mathrm{BMI}$ and Physical Activity of Respondents}

The mean BMI of the respondent was 24.6 (SD of 2.177) with minimum of 19 and maximum of 31 with SD of 2.177

Among a total of 323 respondents $38(11.8 \%)$ of them did regular physical exercise. (Figure 1)

\section{Behavioural Factors}

Among the total respondents (323), only three smoked cigarettes, all of whom had smoked for longer than 10 years although, the amount of cigarettes smoked expressed by pack-year which is medically important if less than 30 packyear. Regarding alcohol use, 11 (3.0\%) of the respondents

Table I Socio-Demographic Characteristics of Diabetic Men Attending at Diabetic Clinic at Dessie Referral Hospital $(\mathrm{N}=323)$, 2020

\begin{tabular}{|c|c|c|c|}
\hline Variables & Category & Frequency & Percentage \\
\hline \multirow[t]{4}{*}{ Age in years } & $18-30$ & 67 & 20.7 \\
\hline & $32-44$ & 71 & 22.0 \\
\hline & $45-59$ & III & 34.4 \\
\hline & $>59$ & 74 & 22.9 \\
\hline \multirow[t]{4}{*}{ Marital status } & Single & 37 & 11.5 \\
\hline & Married & 275 & 85.1 \\
\hline & Divorced & 9 & 2.8 \\
\hline & Widowed & 2 & 0.6 \\
\hline \multirow[t]{3}{*}{ Ethnicity } & Amhara & 312 & 96.6 \\
\hline & Tigray & 9 & 2.8 \\
\hline & Oromo & 2 & 0.6 \\
\hline \multirow[t]{3}{*}{ Religion } & Muslim & 235 & 72.8 \\
\hline & Orthodox Tewahido & 79 & 24.5 \\
\hline & Protestant & 9 & 2.8 \\
\hline \multirow{8}{*}{$\begin{array}{l}\text { Educational } \\
\text { I level }\end{array}$} & Cannot read and & 21 & 6.5 \\
\hline & write & & \\
\hline & Can read and write & 26 & 8.0 \\
\hline & Primary school & 149 & 46.1 \\
\hline & completed & & \\
\hline & High school & 29 & 9.0 \\
\hline & completed & & \\
\hline & College and above & 98 & 30.3 \\
\hline \multirow[t]{3}{*}{ Occupation } & Employed & 99 & 30.7 \\
\hline & Farmer & 144 & 44.6 \\
\hline & Merchant & 80 & 24.8 \\
\hline \multirow{3}{*}{$\begin{array}{l}\text { Monthly } \\
\text { income }\end{array}$} & $<1000 \mathrm{~EB}$ & 128 & 39.6 \\
\hline & $100 \mid-3000$ EB & 88 & 27.2 \\
\hline & $>3000 \mathrm{~EB}$ & 107 & 33.1 \\
\hline \multirow[t]{2}{*}{ Residency } & Urban & 197 & 61.0 \\
\hline & Rural & 126 & 39.0 \\
\hline
\end{tabular}

currently drink alcoholic beverages such as beer (9) and local beer traditionally known as "tela". (Figure 2)

\section{Medical Conditions and Erectile Dysfunction}

More than half $(52 \%)$ of the respondents reported duration since diabetes diagnosis from 1-5 years and high prevalence of the clients had reported that their medication modalities were insulin injectable. About 26 of the respondents had history of diabetic complication. Among the total respondents four of them had history of previous hypertension and one had history of previous cardiac diseases (Table 2)

\section{Prevalence of Erectile Dysfunction}

The discussion of sexual issues, especially those related to male potency may cause embarrassment and stress. This may result in reporting bias, general underestimation or even exaggeration of sexual problems, and even the unwillingness to participate in the study overall. Considering this problem erectile dysfunction was assessed by using well prepared five domain of measuring erectile dysfunction (IIEF-5) to assess the sexual function. The proportion of erectile dysfunction was found to be $58.5 \%(\mathrm{n}=323)$ with the highest proportion having moderate dysfunction (Figure 3).

\section{Factors Associated with Erectile Dysfunction}

Variables which had an association at bivariate analysis (age, duration of DM, types of anti-diabetic medication, types of DM complication, BMI) had unadjusted an association with ED. Following adjustment for potential confounders through multivariate logistic regression analysis age, duration of $\mathrm{dm}$ and types of medication had statistically significant association. Table 3 shows that as the age increase, the odds of having ED increased significantly, age group greater than 59 years had about six times higher odds compared to those 18-30 years old (AOR: 5.523,95\% CI (2.069-14.744). As the duration of diabetes (chronicity) increases the odds of having ED increased significantly, where men with a history of DM $>10$ years were about 20 times more likely to be affected by ED than those with a history of $<5$ years (AOR: 20.622, 95\% CI: 5.663-75.096) (Table 3).

\section{Discussion}

This hospital-based study confirmed that the prevalence of ED is high among DM patients. It further confirmed that age, duration of DM and types of antidiabetic medication 


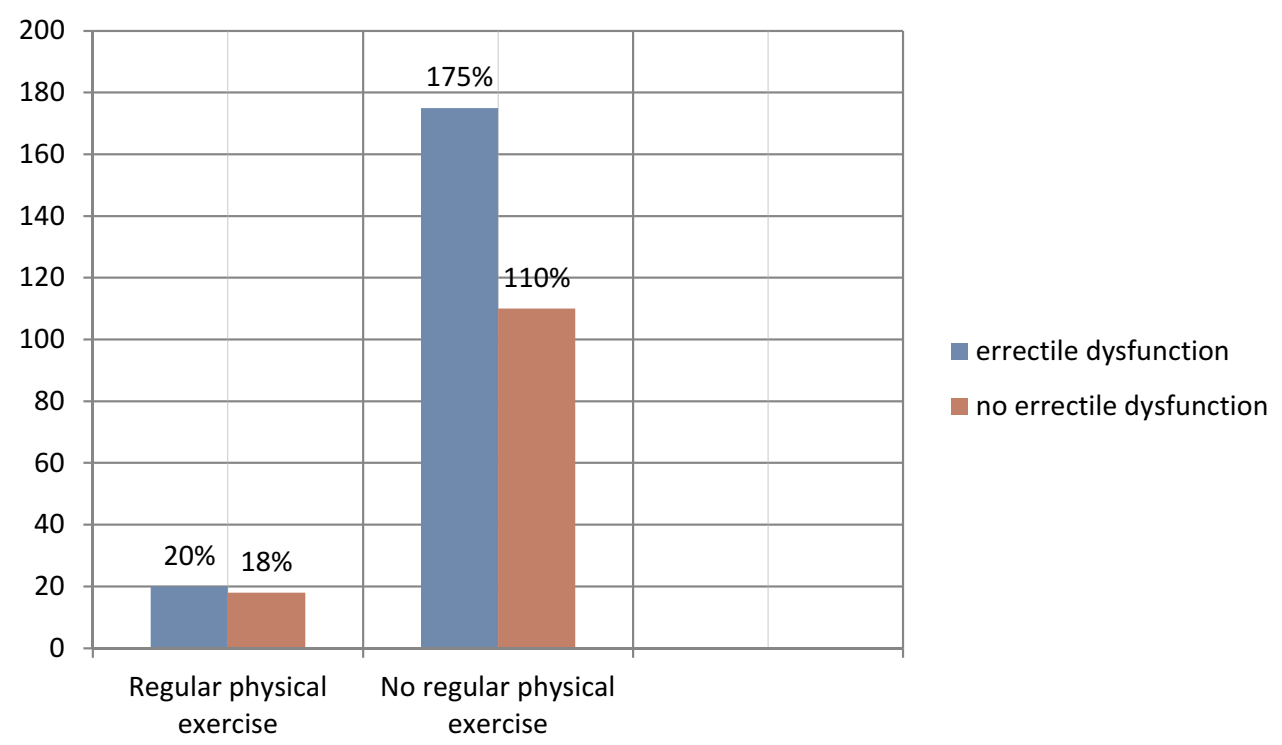

Figure I Erectile dysfunction based on regular physical exercise among male diabetic clients attending Diabetic Clinic at Dessie Referral Hospital ( $N=323), 2020$.

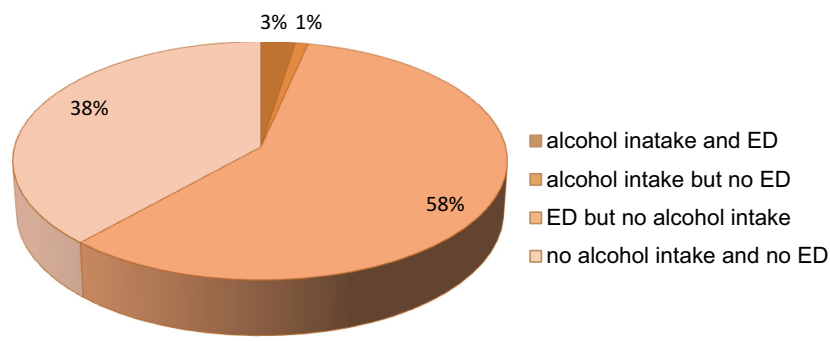

Figure 2 Alcohol intake and erectile dysfunction among diabetic male attending at diabetic clinic at Dessie Referral Hospital ( $n=323), 2020$.

that the patient used were independently associated with the ED and its severity.

In this study, the proportion of erectile dysfunction among men diabetic clients aged 18 years and above was $58.5 \%$ which is lower than other studies conducted in Saudi Arabia, Pakistan, China, Jamaica, Central and North Western zone of Tigray and Felege, Hiwot
Referral Hospital (86.7\%, 80.8\%, 64\%, 64\%, 69.9\%, $85.5 \%$ ), respectively. ${ }^{18,19,21,23,24}$ This difference may be due to a difference in composition of study population, time of the study, difference in socio demographic variation, culture, and lifestyle. However, the proportion observed from the current study is almost comparable to that of the study done in Nigeria, Egypt, Muhimbili with

Table 2 Medical Condition Characteristics of Diabetic Men Attending at Diabetic Clinic at Dessie Referral Hospital (N=323), 2020

\begin{tabular}{|l|l|l|l|}
\hline Variable & Category & Frequency & Percentage \\
\hline Duration of diabetics & $\begin{array}{l}\text { I-5 years } \\
6-10 \text { years } \\
>10 \text { years }\end{array}$ & $\begin{array}{l}168 \\
106 \\
49\end{array}$ & 32 \\
& $\begin{array}{l}\text { Oral medication only } \\
\text { Insulin only }\end{array}$ & 149 & 46.2 \\
\hline Treatment for diabetic complication & $\begin{array}{l}\text { Eye complication } \\
\text { Other complication }\end{array}$ & 174 & 53.9 \\
\hline Type of complication & 11 & 57.7 \\
\end{tabular}




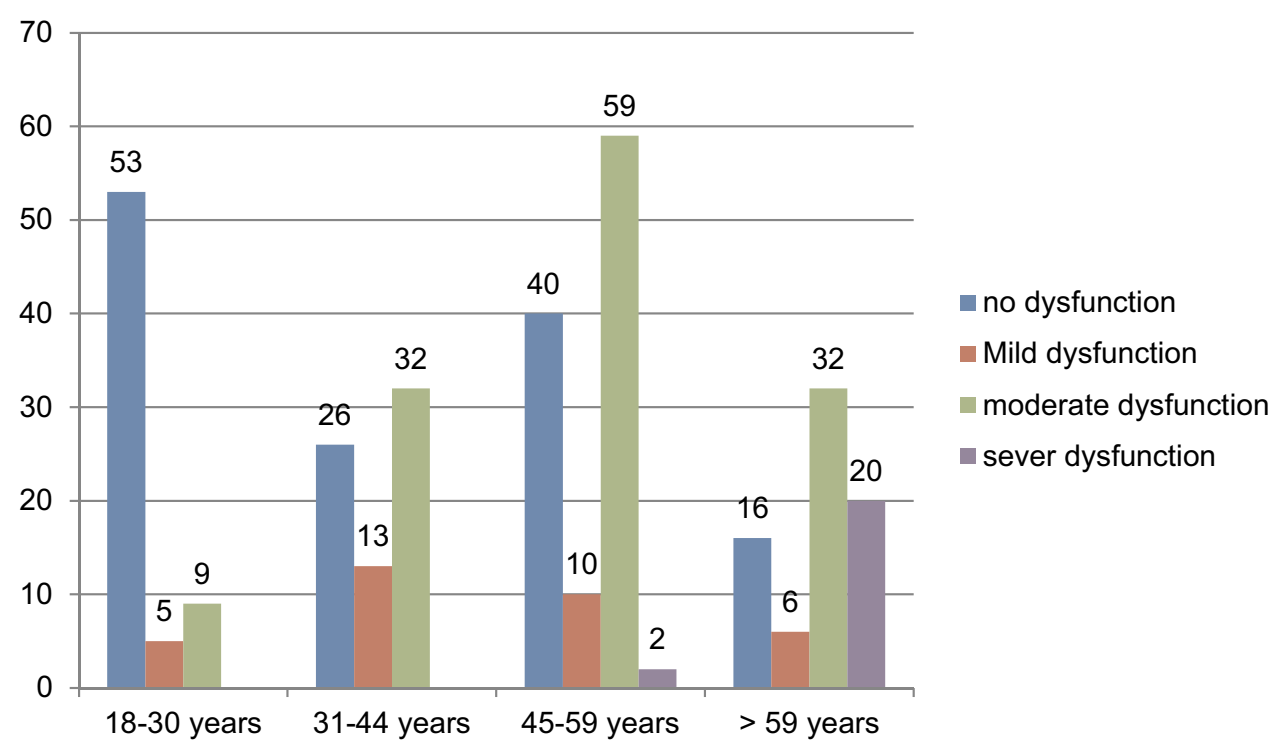

Figure 3 Severity of erectile dysfunction by age groups among male diabetic clients attending Diabetic Clinic at Dessie Referral Hospital (N=323), 2020.

the reported prevalence of $(57.4 \%, 60 . \%, \quad 55 \%)$, respectively ${ }^{8,20,22}$

Data analysis showed that age was positively correlated with $\mathrm{ED}$ in Ethiopian diabetic men. As the age increases the odds of having ED increased significantly; being in the age group 59+ years had about six times higher odds compared to those between 18-30 years. This is similar to the study conducted in Jamaica which showed that as age increased the prevalence of ED also increased. $^{21}$

There is a known relationship between the duration since the diagnosis of diabetes and the prevalence and degree of ED. Furthermore, its impact on the occurrence of complications related to the disease is well-recognized. Longer duration of DM could be associated with poor glycaemic control which in turn affects the vascular system leading to erectile dysfunction. Consistent with previous studies, a positive association between the duration of DM and the proportion of ED was found in the current study which showed that as the duration since clinical diagnosis of diabetes (chronicity) increases, the odds of having ED increased significantly and that men with a history of DM for more than 10 years were about six times more likely to have ED than those with a history of

Table 3 Multivariate Logistic Regression Analysis of Factors Associated with Ed Among Males Diabetic Clients Attending Diabetic Clinic at Dessie Referral Hospital, 2020 ( $N=323), 2020$

\begin{tabular}{|c|c|c|c|c|}
\hline Variables & Erectile Dysfunction & No Erectile Dysfunction & COR(95\% Cl) & AOR(95\% Cl) \\
\hline \multicolumn{5}{|l|}{ Age } \\
\hline $18-30$ years & 14 & 53 & 1.00 & 1.00 \\
\hline $31-44$ years & 45 & 26 & 2.057 (1.017-2.057) & $0.877(0.362-2.124)$ \\
\hline $45-59$ years & 71 & 40 & $2.329(1.091-4.974)$ & $\mathrm{I} .029(0.46 \mathrm{I}-2.299)$ \\
\hline$>59$ years & 58 & 16 & $16.224(7.090-37.127)^{*}$ & $5.523(2.069-14.744)^{* *}$ \\
\hline \multicolumn{5}{|l|}{ Duration of DM } \\
\hline $\mathrm{I}-5$ years & 60 & 108 & 1.00 & 1.00 \\
\hline $6-10$ years & 84 & 22 & $3.349(0.941-11.9120$ & $2.939(0.790-10.933)$ \\
\hline$>10$ years & 44 & 5 & $26.2159(7.823-87.843)^{*}$ & $20.622(5.663-75.096)^{* *}$ \\
\hline \multicolumn{5}{|l|}{ Types of medication } \\
\hline Oral medication & 98 & 51 & 1.00 & 1.00 \\
\hline Insulin injectable & 90 & 84 & $1.609(1.023-2.530)$ & $2.106(1.112-3.988)$ \\
\hline
\end{tabular}

Notes: *Had significant association at $\mathrm{p}<0.2$. $* *$ Statistically associated at $\mathrm{p}<0.05$. 
DM less than 5 years. This result is in line to findings by El-Sakka and Tayeb, where men with a history of DM since diagnosis more than 10 years were three times more likely to report ED than those with history diabetes of less than $<5$ years. ${ }^{20}$ This association can be attributed to the natural process of the diseases which develop over time and other interrelated complications like vascular problems and related medical complications.

\section{Limitations of the Study}

The discussion of sexual issues, especially those of which are related to male potency may cause embarrassment and stress. This may result in reporting bias, general underestimation or even exaggeration of sexual problems, and even the unwillingness to participate in the study which might cause non-response bias. The screening tool for ED was not validated contextually in the local setting as there is scarce studies in Ethiopia.

\section{Conclusion and Recommendation}

The prevalence of ED was $58.5 \%$ in this study and it was shown that that ED is highly prevalent among men with diabetes and increases with duration since diagnosis of DM. There should be measures to treat and control the progression of this neglected condition. The frequency as well as the severity of ED increased with age in patients with diabetes and had significant correlation with the duration since diabetes presence is known.

Recommendations are advised based on this finding to respective bodies and this research report reinforces the need to screen for ED in diabetic patients as it is a routine clinical practice for other chronic medical complications for these patients with DM for early detection, treatment and possibly prevention of complication. The screening for presence or absence of ED can be best done by the use of validated tools for ED in similar settings and population and testing validity or reliability of tools like IIEF questionnaire for local use is strongly recommended.

\section{Disclosure}

The authors declare that they have no competing interests.

\section{References}

1. NIH Consensus Conference. Impotence. NIH consensus development panel on impotence. JAMA. 1993;270(1):83-90. doi:10.1001/ jama.1993.03510010089036
2. Sáenz de Tejada I, Anglin G, Knight JR, Emmick JT. Effects of tadalafil on erectile dysfunction in men with diabetes. Diabetes Care. 2002;25(12):2159-2164. doi:10.2337/diacare.25.12.2159

3. Kubin M, Wagner G, Fugl-Meyer AR. Epidemiology of erectile dysfunction. Int $J$ Impot Res. 2003;15(1):63-71. doi:10.1038/sj. ijir.3900949

4. Shiri R, Hakama M, Häkkinen J, Tammela T, Auvinen A, Koskimäki J. Relationship between smoking and erectile dysfunction. Int J Impot Res. 2005;17(2):164-169.

5. Selvin E, Burnett AL, Platz EA. Prevalence and risk factors for erectile dysfunction in the US. Am J Med. 2007;120(2):151-157. doi:10.1016/j.amjmed.2006.06.010

6. Cho NH, Ahn CW, Park JY, et al. Prevalence of erectile dysfunction in Korean men with type 2 diabetes mellitus. Diabet Med. 2006;23 (2):198-203. doi:10.1111/j.1464-5491.2005.01789.x

7. Siu SC, Lo SK, Wong KW, Ip KM, Wong YS. Prevalence of and risk factors for erectile dysfunction in Hong Kong diabetic patients. Diabet Med. 2001;18(9):732-738. doi:10.1046/j.0742-3071.2001.00557.x

8. Oyelade BO, Jemilohun AC, Aderibigbe SA. Prevalence of erectile dysfunction and possible risk factors among men of South-Western Nigeria: a population based study. Pan Afr Med J. 2016;24:124.

9. Deutsch S, Sherman L. Previously unrecognized diabetes mellitus in sexually impotent men. JAMA. 1980;244(21):2430-2432.

10. Braun M, Wassmer G, Klotz T, Reifenrath B, Mathers M, Engelmann U. Epidemiology of erectile dysfunction: results of the 'Cologne Male Survey'. Int J Impot Res. 2000;12(6):305-311. doi:10.1038/sj.ijir.3900622

11. Marumo K, Nakashima J, Murai M. Age-related prevalence of erectile dysfunction in Japan: assessment by the international index of erectile function. Int J Urol. 2001;8(2):53-59. doi:10.1046/j.14422042.2001.00258.x

12. Johannes CB, Araujo AB, Feldman HA, Derby CA, Kleinman KP, McKinlay JB. Incidence of erectile dysfunction in men 40 to 69 years old: longitudinal results from the Massachusetts male aging study. J Urol. 2000;163(2):460-463. doi:10.1016/S0022-5347(05)67900-1

13. Msc AM. Erectile dysfunction in diabetes: an overview. Int $J$ Innov Stud Med Sci. 2019;3(1):13-14.

14. Al-Hunayan A, Al-Mutar M, Kehinde EO, Thalib L, Al-Ghorory M. The prevalence and predictors of erectile dysfunction in men with newly diagnosed with type 2 diabetes mellitus. BJU Int. 2007;99 (1):130-134. doi:10.1111/j.1464-410X.2006.06550.x

15. Nunes KP, Labazi H, Webb RC. New insights into hypertension-associated erectile dysfunction. Curr Opin Nephrol Hypertens. 2012;21(2):163-170. doi:10.1097/MNH.0b013e32835021bd

16. Mirone V, Imbimbo C, Palmieri A, Longo N, Fusco F. Erectile dysfunction after surgical treatment. Int $J$ Androl. 2003;26 (3):137-140. doi:10.1046/j.1365-2605.2003.00384.x

17. Feldman HA, Goldstein I, Hatzichristou DG, Krane RJ, McKinlay JB. Impotence and its medical and psychosocial correlates: results of the Massachusetts Male Aging Study. J Urol. 1994;151 (1):54-61. doi:10.1016/S0022-5347(17)34871-1

18. Shaeer KZ, Osegbe DN, Siddiqui SH, Razzaque A, Glasser DB, Jaguste V. Prevalence of erectile dysfunction and its correlates among men attending primary care clinics in three countries: Pakistan, Egypt, and Nigeria. Int J Impot Res. 2003;15(Suppl S1): S8-S14. doi:10.1038/sj.ijir.3900971

19. Xu Y, Zhang Y, Yang Y, Liu L, Chen Y, Liu X. Prevalence and correlates of erectile dysfunction in type 2 diabetic men: a population-based cross-sectional study in Chinese men. Int J Impot Res. 2019;31(1):9-14.

20. El-Sakka AI, Tayeb KA. Erectile dysfunction risk factors in noninsulin dependent diabetic Saudi patients. $J$ Urol. 2003;169 (3):1043-1047. doi:10.1097/01.ju.0000050080.21839.f9

21. Peter J, Riley C, Layne B, Miller K, Walker L. Prevalence and risk factors associated with erectile dysfunction in diabetic men attending clinics in Kingston, Jamaica. J Diabetol. 2012;2:2. 
22. Mutagaywa RK, Lutale J, Muhsin A, Kamala BA. Prevalence of erectile dysfunction and associated factors among diabetic men attending diabetic clinic at Muhimbili National Hospital in Dar-esSalaam, Tanzania. Pan Afr Med J. 2014;17:227. doi:10.11604/ pamj.2014.17.227.2695

23. Seid A, Gerensea H, Tarko S, Zenebe Y, Mezemir R. Prevalence and determinants of erectile dysfunction among diabetic patients attending in hospitals of central and northwestern zone of Tigray, northern Ethiopia: a cross-sectional study. BMC Endocr Disord. 2017;17(1):16.
24. Walle B, Lebeta KR, Fita YD, Abdissa HG. Prevalence of erectile dysfunction and associated factors among diabetic men attending the diabetic clinic at Felege Hiwot Referral Hospital, Bahir Dar, North West Ethiopia, 2016. BMC Res Notes. 2018;11(1):130. doi:10.1186/ s13104-018-3211-2

\section{Publish your work in this journal}

Diabetes, Metabolic Syndrome and Obesity: Targets and Therapy is an international, peer-reviewed open-access journal committed to the rapid publication of the latest laboratory and clinical findings in the fields of diabetes, metabolic syndrome and obesity research. Original research, review, case reports, hypothesis formation, expert opinion and commentaries are all considered for publication. The manuscript management system is completely online and includes a very quick and fair peer-review system, which is all easy to use. Visit http://www.dovepress.com/testimonials.php to read real quotes from published authors. 